\title{
Adolescent-Adult Non-metastatic Ewing Sarcoma- Experience from a large developing country
}

Jyoti Bajpai ${ }^{1}$, Goutam Panda ${ }^{1}$, Arun Chandrasekharan ${ }^{2}$, Prabhat Bhargava ${ }^{1}$, Sujay Srinivas $^{1}$, Siddhartha Laskar ${ }^{1}$, Sonal Dandekar ${ }^{1}$, Smruti Mokal ${ }^{1}$, Bharat Rekhi ${ }^{1}$, Nehal Khanna $^{1}$, Nandini Menon ${ }^{1}$, Vijay Patil ${ }^{1}$, Vanita Noronha ${ }^{1}$, Amit Joshi ${ }^{1}$, Kumar Prabhash ${ }^{1}$, Sripad Banavali ${ }^{1}$, and Sudeep Gupta ${ }^{1}$

${ }^{1}$ Tata Memorial Centre

${ }^{2}$ Tata Memorial Hospital

February 15, 2021

\begin{abstract}
Background Outcomes of Ewing sarcoma (ES) in low and middle income countries lags behind the rest of the world owing to multiple tumoral, logistical and socio-economic factors. The data of outcomes and toxicity in these countries is sparse, especially in the adolescent and adult (AA) population and merits exploration Procedure This was a retrospective analysis of prospectively collected data of non-metastatic AA-ES patients, who received standard institutional combination chemotherapy regimen (EFT2001) along with surgery or definitive radiotherapy. Various cohorts were analyzed for treatment-related toxicities, event- free survival (EFS) and overall survival (OS). Results There were 235 patients (primary safety cohort, PSC) with median age of 23 years. One hundred and ninety six were treatment naïve (primary efficacy cohort, PEC) and of these 119 had surgery. In PEC, at a median follow up of 36.4 months, estimated 5 year EFS and OS were $60.9 \%$ (95\% CI 53.1\% - 69.9\%) and 84.5\% (95\% CI $77.7 \%-91.9 \%)$, respectively. Of these, 158 complying with intended treatment, had an estimated 5 year EFS of $63.1 \%$ (95\% CI 54.8\%-72.6\%). In multivariate analysis, good prognostic factors included longer symptom duration, [?] 99\% necrosis and treatment completion. Among PSC, grade 3-4 toxicities were febrile-neutropenia (50.6\%), anemia (55.3\%), peripheral neuropathy $(15.7 \%)$, with $3(1.3 \%)$ chemo-toxic deaths. Conclusions The outcomes of AA non-metastatic ES patients treated with EFT-2001 regimen were comparable to those reported by others, with acceptable toxicity and can be considered as standard-of-care, especially in LMICs.
\end{abstract}

\section{Hosted file}

AA ES_manuscript.pdf available at https://authorea.com/users/395932/articles/509055adolescent-adult-non-metastatic-ewing-sarcoma-experience-from-a-large-developing-country

\section{Hosted file}

Table_1.pdf available at https://authorea.com/users/395932/articles/509055-adolescent-adultnon-metastatic-ewing-sarcoma-experience-from-a-large-developing-country

\section{Hosted file}

Table_2.pdf available at https://authorea.com/users/395932/articles/509055-adolescent-adultnon-metastatic-ewing-sarcoma-experience-from-a-large-developing-country

\section{Hosted file}

Table_3.pdf available at https://authorea.com/users/395932/articles/509055-adolescent-adultnon-metastatic-ewing-sarcoma-experience-from-a-large-developing-country 

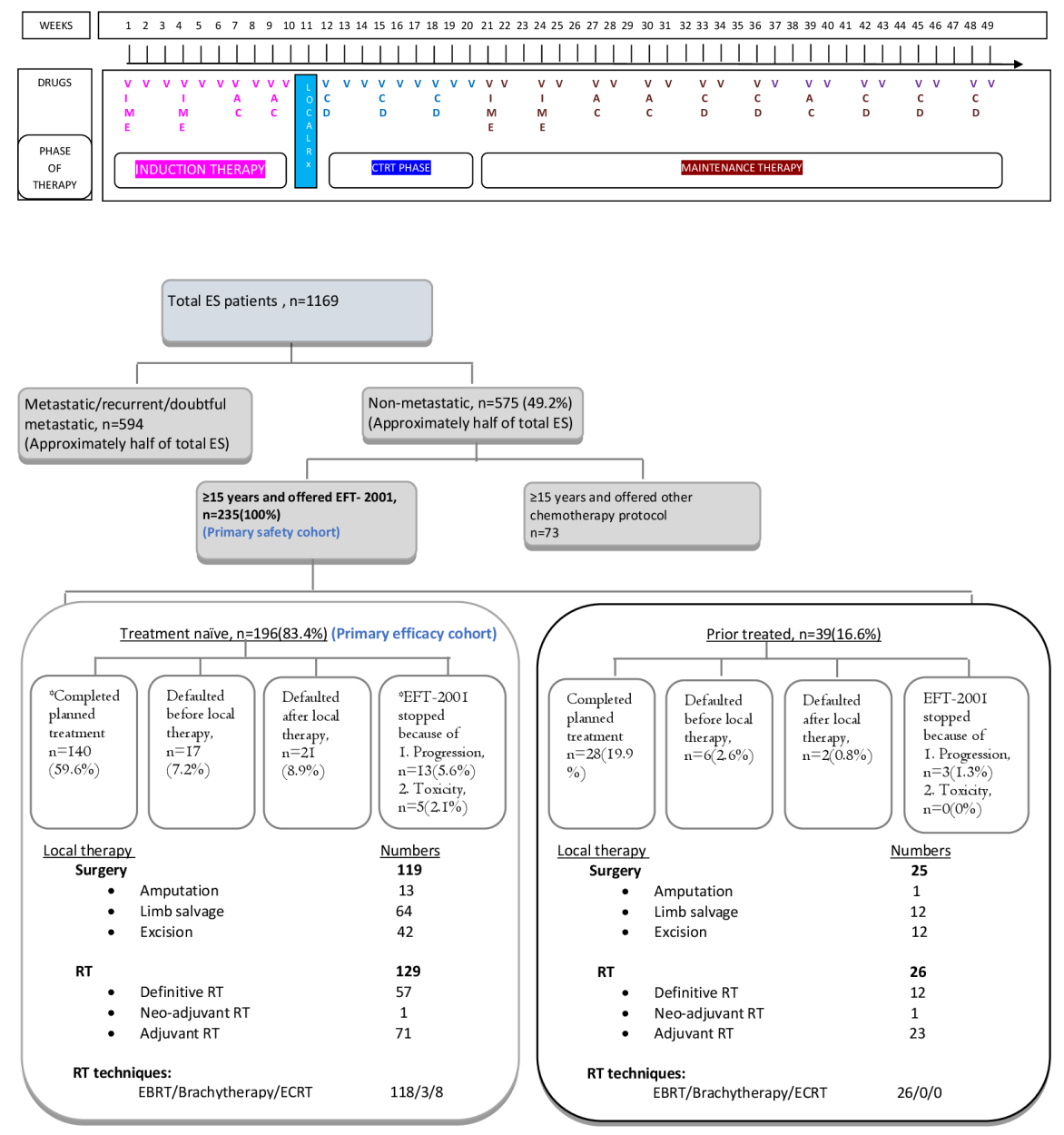

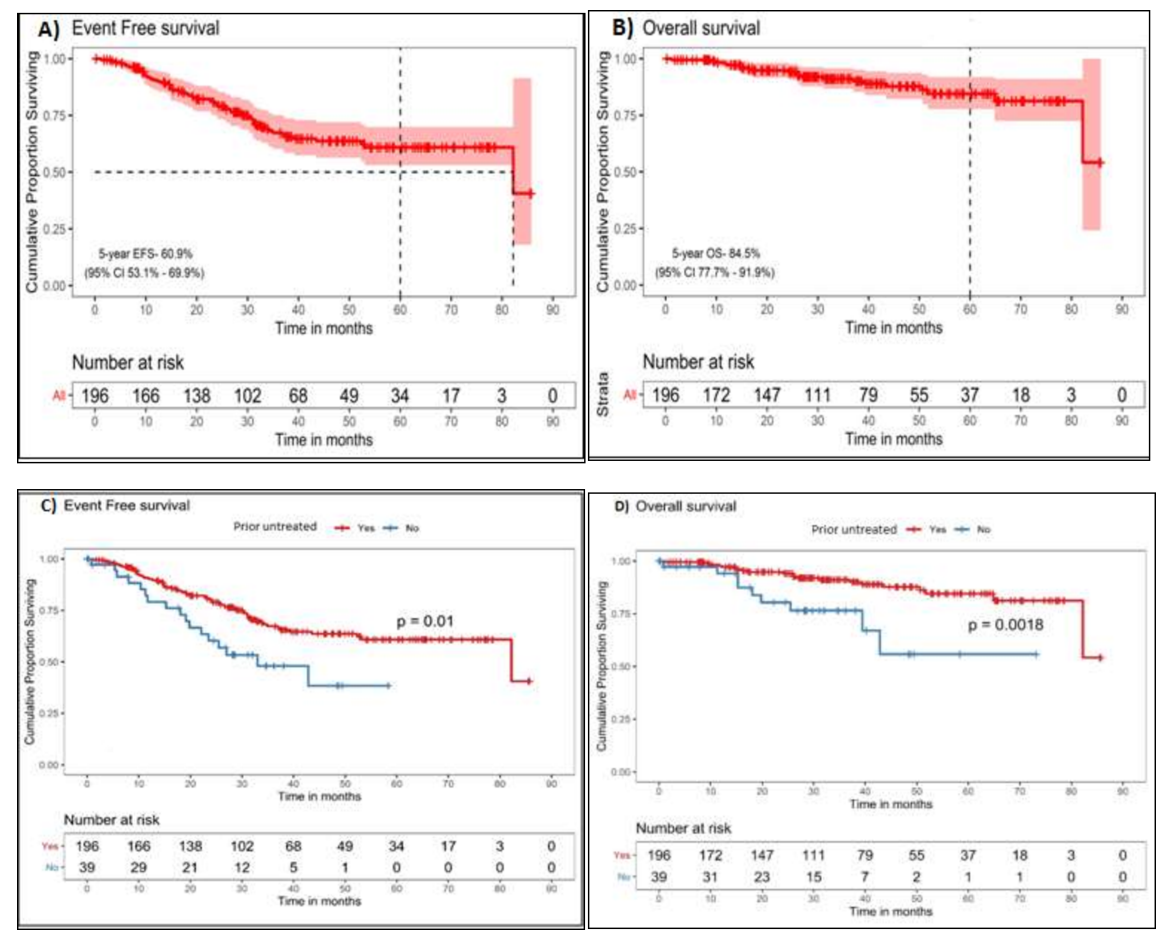